\title{
Design of a Mobile-Internet-Based Management Platform for Materials Transportation of Road and Bridge Engineering
}

\author{
Hu Chunsheng, a, Tang Bo ${ }^{1, b}$, Li Yaonan ${ }^{1, c}$ and Shi Jingjing ${ }^{2, d}$ \\ ${ }^{1}$ School of Mechanical Engineering, Ningxia University, Ningxia 750021, China \\ 2 Ningxia road and bridge engineering co., LTD, Ningxia 750021, China \\ ajeadean@163.com, b50502026@qq.com, ‘601154336@qq.com, dtime99@163.com
}

\begin{abstract}
Keywords: Road and Bridge; Logistics; Materials Transportation; Mobile Internet
Abstract. Materials transportation is the basis of road and bridge construction, which is an important part of national infrastructure construction. Materials transportation processes of road and bridge projects have some deficiencies in process management, information exchange, status monitoring and process optimization because of its organization and execution features. Aim to improve these deficiencies, a Mobile-Internet-based management platform for materials transportation of road and bridge project is proposed. Firstly, current materials transportation mode and its defects are elaborated and based on the analysis of its complexity and particularity, some detailed requirements for a management platform is presented; Secondly, based on the simplification of materials transportation mode, software structure of a management platform is designed and its main functional modules are designed and elaborated; Finally, this platform is implemented and transportation processes are tested, the result shows that this system can solve problems include nonstandard process, conflicting data source, low efficiency of communication, difficulty of real-time monitoring, data synchronization and data collection.
\end{abstract}

\section{Introduction}

Domestic investment in road and bridge construction, which is an important part of national infrastructure construction, increased year by year in China. For the construction problems of road and bridge engineering, a large number of domestic researches focused on construction site management, project quality control and specific technical issues, while material transportation researches are hardly seen $[1,2]$.

As the most basic step in road and bridge construction, material transportation affects the project's progress. Due to the organization structure, construction characteristics and other reasons, the material transportation of road and bridge project has some deficiencies or defects in transportation process control, information exchange, condition monitoring, data record, data analysis and process optimization. All these issues directly or indirectly affect the efficiency, cost and quality of project implementation. The IoT (Internet of Things) [3], mobile Internet [4,5] and other related technologies provide an opportunity to improve these deficiencies. By using mobile phone accessed in Internet, not only transportation process control and status monitoring can be realized, but also a large number of transportation data can be accumulated and analyzed to provide support and reference for transportation process optimization.

Based on detailed analysis of material transportation process in road and bridge project, this paper designs and implements a mobile-internet-based transportation management platform, which manages the whole life cycle of material transportation process, to accomplish standardized transportation process, uniform data source, information synchronization, high efficiency communication and data collection. The design process and the main structure of this system are described in the following.

\section{Analysis of Material Transportation Process in Road and Bridge Construction}

Material Transportation Mode. The material transportation of the road and bridge engineering belongs to the category of logistics transportation [6], but it is more complicated than ordinary 
logistics transportation with only three sides include transportation demand side, the carrier and the transportation destination side. Although different road and bridge engineering companies have different transportation process, but most of them can be abstracted to a classic model, as shown in Figure 1.

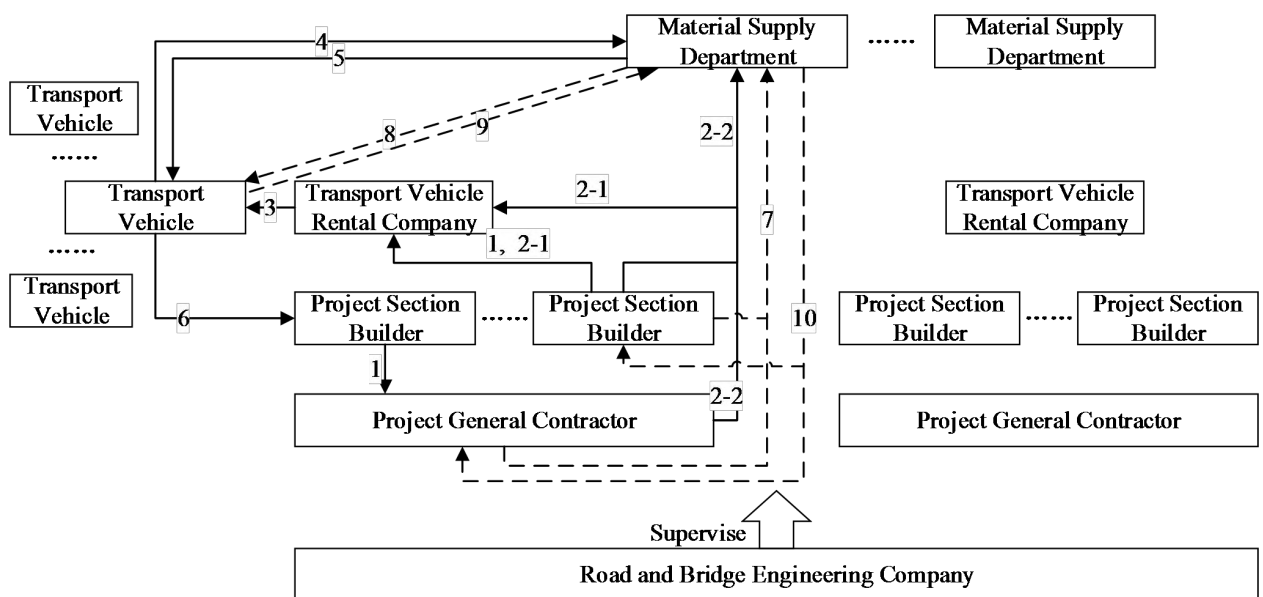

Fig. 1 A typical pattern diagram for materials transportation of road and bridge project

Ideally, the transportation mode consists of six main steps, as shown in Figure 1 in solid line:

Step1: Project Section Builders submit materials requirements to Project General Contractors. (Or they can directly order materials by themselves.)

Step2: Project General Contractors/Project Section Builders order materials from Material Supply Department, and in the meanwhile book transportation vehicles from Transportation Vehicle Rental Company.

Step3: Transportation Vehicle Rental Company arranges vehicles to take the transportation mission.

Step4: Vehicles go to the Material Supply Departmen to load materials.

Step5: Material Supply Department tells Vehicles about transportation destination.

Step6: Vehicles transit materials to Project Section Builders.

There are a lot of communication actions in the transportation process, and a typical one is shown in Figure 1 in dotted line:

Step7: Project General Contractors/Project Section Builders want to know the transportation state of their transportation missions.(They can only acquire the information from the Material Supply Department because all the vehicles cannot directly communication with them.)

Step8: Material Supply Department contacts vehicles for their state.

Step9: Vehicles report their state.

Step10: Material Supply Department give feedback to Project General Contractors/Project Section Builders.

In practice, the main problems exposed by this transportation mode include: 1) too many participant result in swollen structure and complex process; 2) no public information interactive environment led to the information can not be updated and synchronized which cause increased information error possibility and inefficient communication; 3) transportation process is not standardized and any changes will bring unpredictable, complex business adjustment process and great communication costs; 4) real-time monitoring cannot be implemented; 5) life-cycle data cannot be accurately collected and recorded, thus can not provide effective support for the analysis, forecasting and optimization of the transportation process.

Above problems are mainly caused by the complexity and particularity of material transportationation of road and bridge project.

Complexity and Particularity of Material Transportation. Complexity and particularity of material transportation are mainly caused by three aspects: organization form, construction characteristics and management tools.

Organization structure leads to the diversity of roles. The organizational structure of the road and bridge construction project involves a number of participants are shown in Figure 1. Each road and 
bridge company has its own organization structure, and according to the actual situation, some participants are controlled by the company, and some are autonomous. In addition, each participant has a variety of different roles in different forms connected to the material transportation process. This will inevitably lead to more complex and chaotic system which brings poor performance, low efficiency and high operating costs to material transportation process.

Construction characteristics lead to the complexity of material transportation process. Road and bridge construction requires a large number of different types of materials include sand and gravel, cement, steel, timber and other materials. According to specific construction situations, every transportation mission has different material demands. Sometimes one transportation mission needs a large number of transportation vehicles in a very short period of time to transportation a large number of materials, and sometimes one transportation mission only needs one vehicle to transportation several types of materials. When several projects are carried out simultaneously, there will be dozens of Section Builders who is always submitting new transportation missions, and this situation will grow more chaotic without centralized control. In addition, on one hand empty vehicles go back from the Section Builders with no profits, on the other hand other Section Builders on these vehicles' way back may have the need to transportation equipment back to city, while not knowing that some vehicles is going back near them.

Different management methods employed by various participants have different degree of digitization, and this fact causes big troubles to information synchronization and updating. Because some participants are business autonomy, information cannot be directly updated and synchronized among multiple parties, which lead to poor communication of information, difficult data collection and recording and other issues. Besides, most of the Section Builders are in the wild where permanent connections such as DSL (Digital Subscriber Line) and Cable television lines are unavailable.

A Mobile-Internet-Based management platform for material transportation can be built to solve these problems[7]:1) all transportation processes can run on one platform with standardized process and same data sources which can avoid the information error; 2) every participant can use his mobile phone to do business activities or monitor related transportation missions everywhere; 3) every vehicle driver with a mobile phone can access his real-time geographical location acquired by GPS (Global Position System) module into the system; 4) every participant can check his transportation mission's information on the GIS (Geographic Information System) software in his mobile phone; 5) life-cycle data can be collected for further use.

\section{Design of Mobile-Internet-Based Management Platform}

Before the construction of this system, the transportation model has to be classified and simplified.

Cargo-Based Model. This model states that there are some materials need to be transported from Material Supply Department to Project Section Builder. According to actual situation, this mode can be divided into two cases, one is that a large amount of materials need a large number of vehicles, and in this case, a transportation mission is divided into several transportation tasks and each vehicle corresponds to one task; the other one is that a relatively small amount of materials less than the load capacity of a vehicle, then a vehicle can carry a number of same transportation tasks and each vehicle corresponds to several tasks.

Vehicle-Based Model. This model states that there is an idle vehicle can perform transportation mission. In this mode, the departure location and destination location is determined by vehicle's driver. In this case, the vehicle can accept a single or multiple transportation missions based on its actual carrying capacity. The vehicle-based mode does not split transportation mission, and it means that each transportation activity is one transportation mission.

Empty-Vehicle-Return Model. This model states that there is an idle vehicle move back from one fixed point A to one fixed point B after the end of one transportation task. Like the Vehicle-Based Mode, each transportation activity is one transportation mission.

Rebuild of Typical Material Transportation Mode. A typical material transportation mode is rebuilt as shown in Fig. 2. 


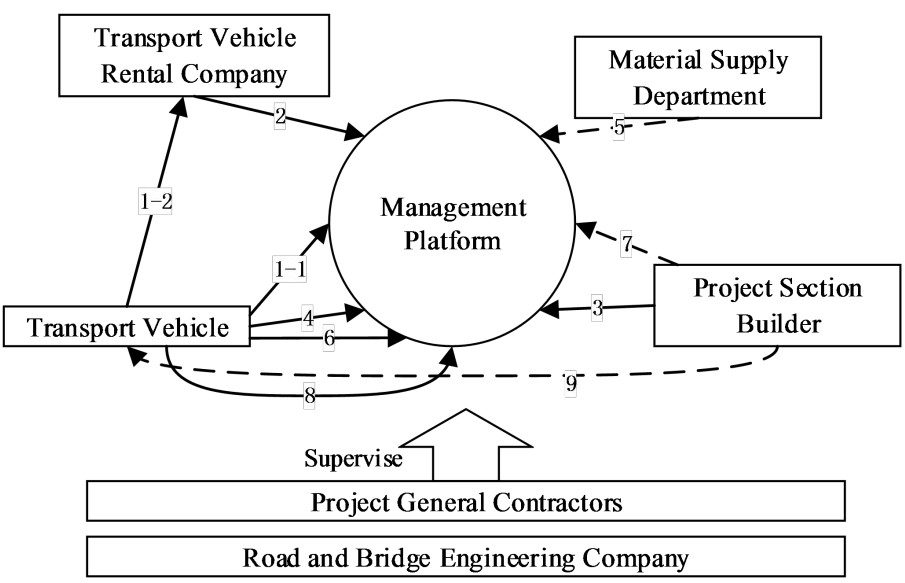

Fig. 2 A rebuilt pattern diagram for materials transportation of road and bridge project

In this mode, process of cargo-based mode is shown from Step1 to Step7.

Step 1-1: Registration of transportation vehicles to the Management Platform;

Step 1-2: Qualification confirmation of transportation vehicles by Transportation Vehicle Rental Company;

Step 2: Transportation Vehicle Rental Company authorized the Transportation Vehicles to meet the conditions;

Step 3: Project Section Builders submit transportation missions to Management Platform;

Step 4: Transportation Vehicles view the details of all transportation missions and accept some;

Step 5: Material Supply Department loads the vehicles according to their transportation mission details;

Step 6: Transportation Vehicles transportation materials to Project Section Builder.

Step 7: Project Section Builder can monitor the transportation state through the system anytime.

Process of vehicle-based mode and empty-vehicle-return mode is shown from Step 8 to Step 9.

Step 8: Transportation Vehicles submit information to the platform;

Step 9: Project Section Builders view information and negotiate with Transportation Vehicles to make a transportation mission.

In this mode, the vehicle-based mode and empty-vehicle-return mode are simplified to one online information release and offline negotiation process. The most import cargo-based model's life cycle diagram is shown in Fig. 3.

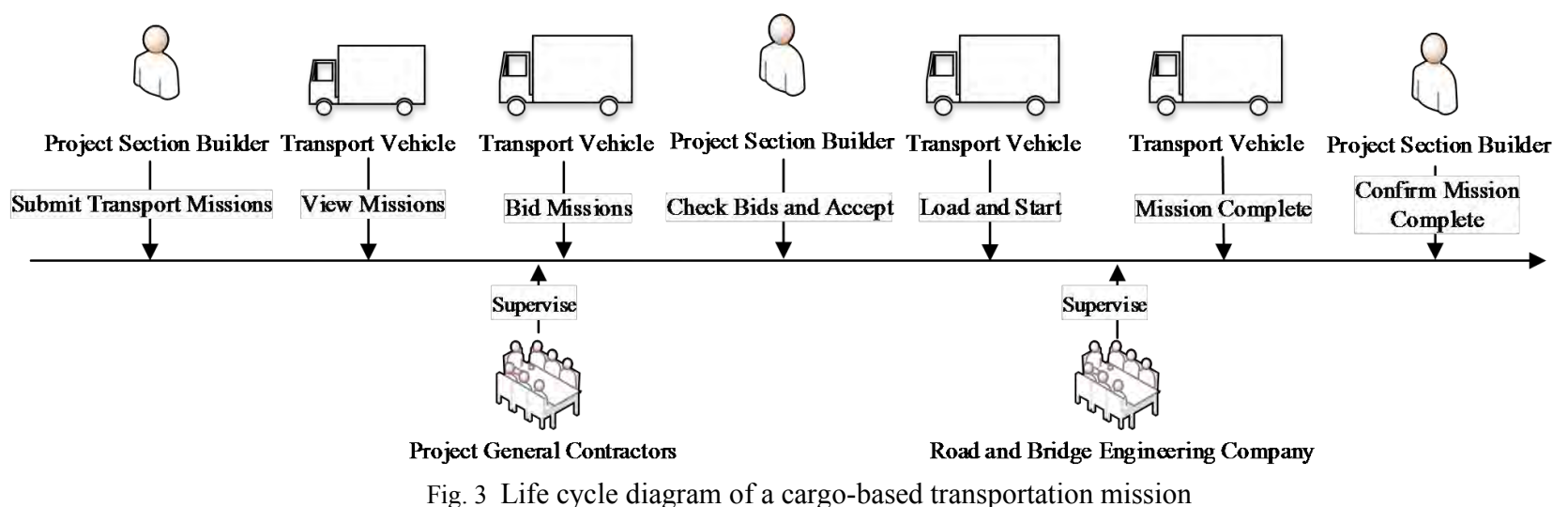

Software architecture and function modules. According to the above analysis, software architecture and function modules are designed and shown Fig. 4: 


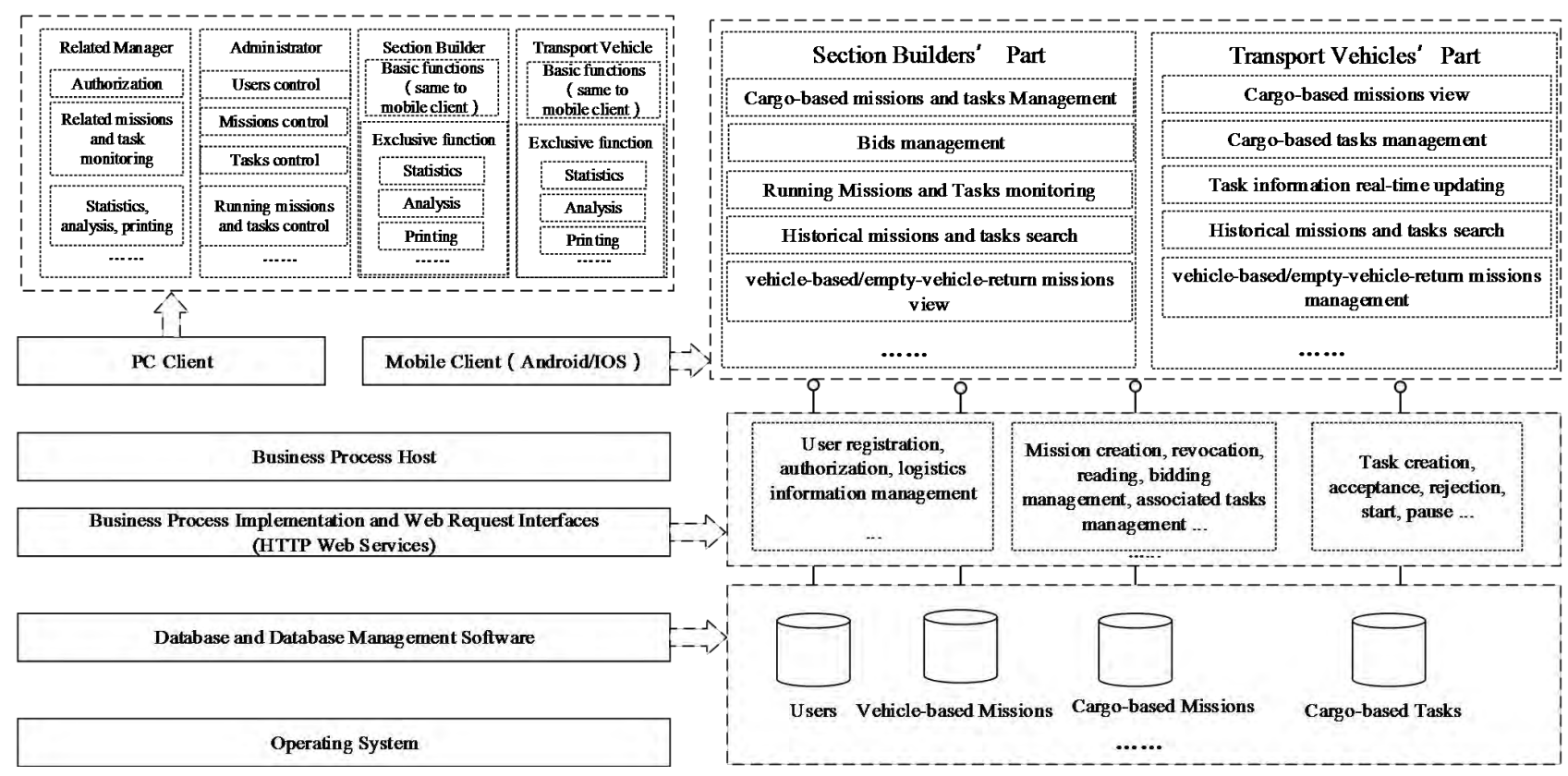

Fig. 4 Hierarchy and functional module structure of the management platform

As shown in Figure 4, the whole system is divided into five layers:

- The operating system provides a base operating environment;

- The database stores all relevant user classifications and information, all cargo-based missions and tasks, all vehicle-based/empty-vehicle-return missions and other information;

- The business process implementation and the Web request interface implement various business logic into different Web services that can be invoked through the HTTP GET / POST methods;

- Business process host bearing the web services and posting them to the Internet;

- The mobile Client, which is used on the mobile phone, is divided into two modules. One is for Section Builders and one is for Transportation Vehicles. The Section Builders can achieve management of transportation missions, bids and tasks. At the same time, it can monitor the running transportation missions and tasks in real time, and can also carry out vehicle-based/empty-vehicle-return missions query, historical transportation missions and tasks searching and other operations. The Transportation Vehicle side can achieve management of vehicle-based/empty-vehicle-return missions, bids and transportation tasks. At the same time, the transportation vehicle side has a very important function to update its own geographical location to the server in real-time.

- The PC Client contains multiple subsystems, where the basic functions of the Section Builder subsystem and the transportation vehicle subsystem are the same as those on the mobile side, but the functions of the statistics, analysis and report printing are only available on the PC side. The administrator system is responsible for managing all users, all transportation missions and tasks. The system of the relevant manager can give authority to transportation vehicles, view the transportation missions and tasks associated with themselves, perform statistics, analysis and printing, but they cannot do any changes to these missions and tasks information.

\section{Implementation of Mobile-Internet-Based Management Platform}

Based on the above, a platform of materials transportation for Ningxia road and bridge engineering co., LTD is developed. Taking the cargo-based transportation missions as an example, Fig. 5 shows the main operation process on Android-based mobile phone. 


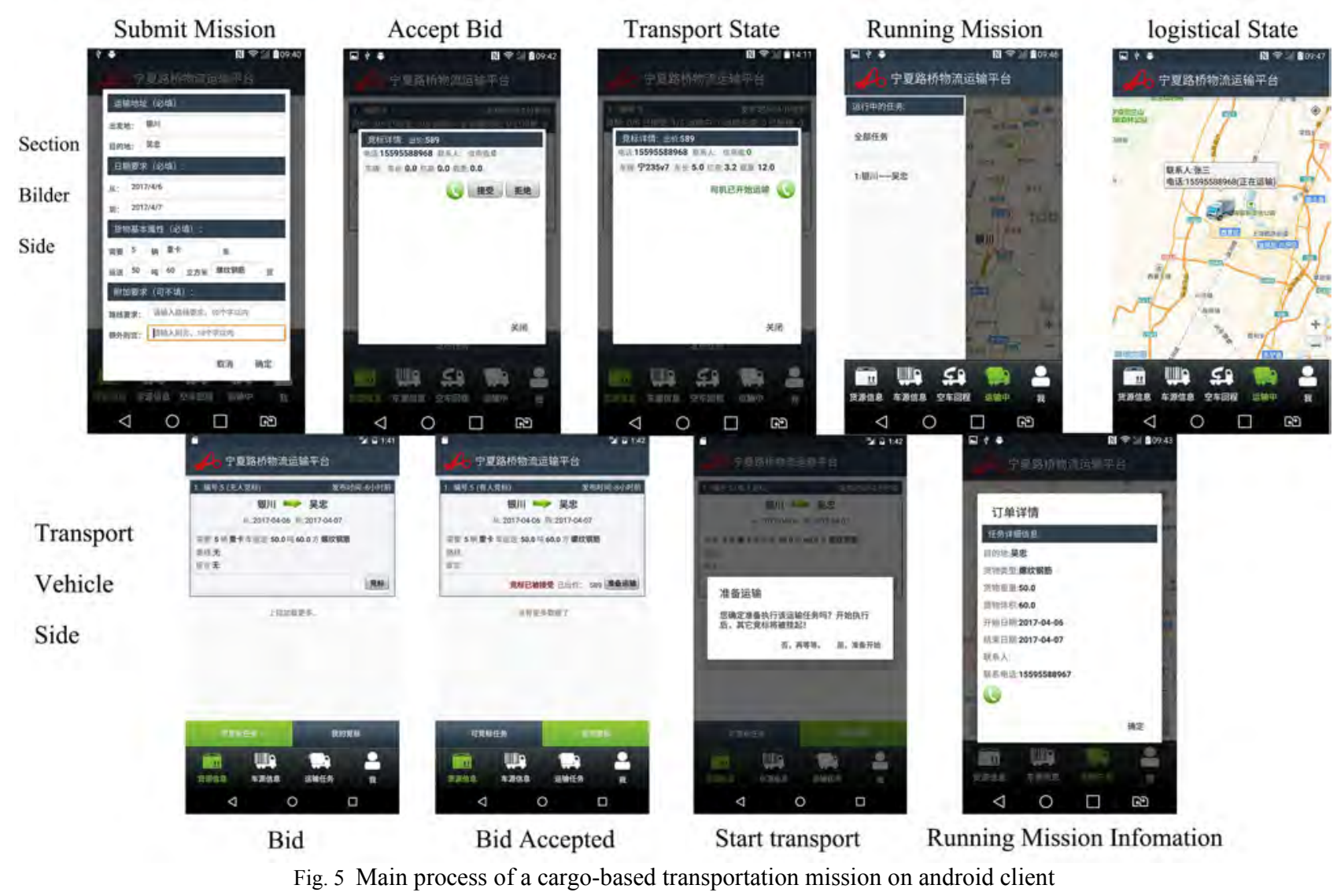

\section{Conclusions}

This paper designs a management platform of material transportation for road and bridge engineering. Take the mobile Internet as its basis, the whole life cycle of material transportation is managed, which effectively solves some problems. Firstly, transportation process is standardized by role and function definition, PC client and mobile client function division, so that each participant in the transportation process can clearly perform its function; Secondly, a unified data source is built so that all the information can be timely updates and synchronization, and errors caused by unsynchronized information has completely disappeared; Thirdly, multi-party can achieve convenient communication through the platform and the communication efficiency is greatly improved; Fourthly, transportation processes can be real-time monitored and adjustment can be made timely; Finally, life-cycle information can be collected and recorded, thus further studies on the improve of transportation process can be acquired.

\section{Acknowledgements}

This work was supported by Ningxia road and bridge engineering co., LTD and financially supported by the Research Starting Funds for Imported Talents, Ningxia University (BQD2014020).

\section{References}

[1] F. R. Yang. Difficulties and strategies of Road \&bridge engineering site construction management. Transportationation Construction \& Management. Vol. 20(2014) ,p.112-113+116. [In Chinese]

[2] Editorial department of China Journal of Highway and Transportation. Review on China's Traffic Engineering Research Progress. China Journal of Highway and Transportation. Vol. 06(2016), p. 1-161. [In Chinese]

[3] L. Atzori, A. Iera, and G. Morabito. The Internet of Things: A survey. Comput. Netw., vol.54(2010), p. 2787-2805, 2010. 
[4] G. Wu, S. Talwar, K. Johnsson, et al. M2M: From mobile to embedded internet[J]. IEEE Communications Magazine, vol. 49(2011).

[5] D. Schweer, J. C. Sahl. In: The Drivers of Digital Transformation. Chapter: The Digital Transformation of Industry - The Benefit for Germany. Springer International Publishing (2017). [6] F. Lasserre. Logistics and the Internet: transportationation and location issues are crucial in the logistics chain. Journal of Transportation Geography,Vol. 12(2004), p. 73-84.

[7] L. Feng. Intelligent logistics and distribution system based on Internet of Things, in :Advanced Information Management, Communicates, Electronic and Automation Control Conference (IMCEC), 2016 IEEE. IEEE (2016) 